\title{
Failure Mechanism and Bearing Capacity of Footings Buried at Various Depths in Spatially Random Soil
}

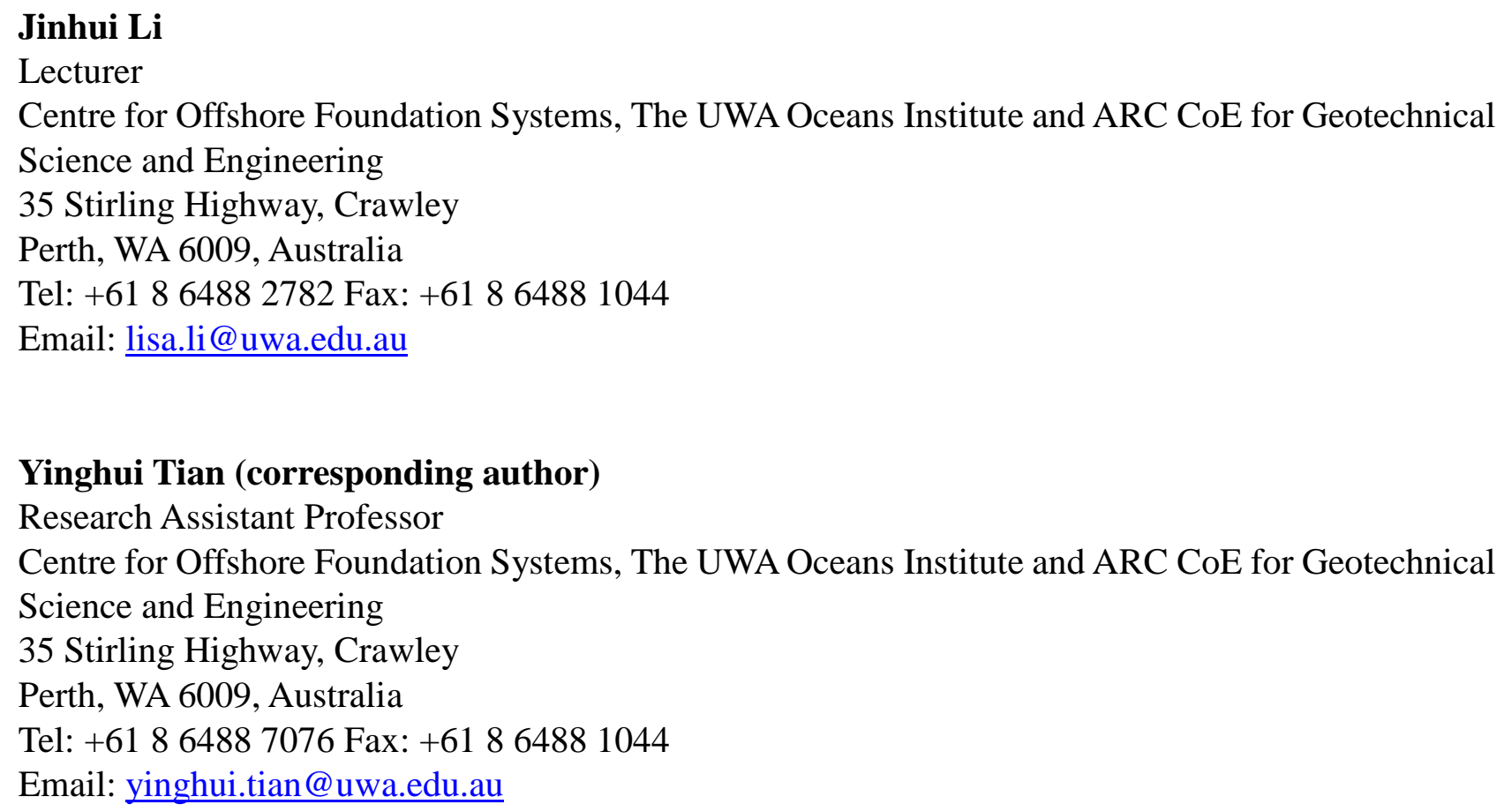




\section{Failure Mechanism and Bearing Capacity of Footings Buried at Various Depths in Spatially Random Soil}

\section{Abstract:}

The objective of this paper is to demonstrate how the spatial variability of random soil affects the failure mechanism and the ultimate bearing capacity of foundations buried at various depths. A non-linear finite element analysis combined with random field theory is employed to explore the vertical capacity of foundations embedded at different depths in random soil. Different possibilities of shear failures resulting from spatial patterns of soil are demonstrated and used to explain the significant discrepancy between the bearing capacity of the random soil and that of uniform soil. The effect of the spatial pattern of the soil on the development of shear planes is also investigated, with the coefficients of variation for the bearing capacity demonstrated to be closely related to the shear plane length. Results of the statistical variation in the bearing capacity are provided for different embedment depth and these are also reported as the failure probability of the footing against using the established uniform soil bearing capacity. Safety factors are proposed for foundations at different levels of failure probability. This study provides a thorough understanding of the failure mechanisms of footings in random soil, especially where structures can penetrate deeply into soil.

\section{CE Database subject headings:}

Load bearing capacity; Probability; Footings; Monte Carlo method; Clays.

\section{Author keywords:}

Bearing capacity; Random field; Failure mechanism; Buried foundation; Statistical analysis; Cohesive soil; Offshore engineering. 


\section{Introduction}

The vertical bearing capacity of a shallow foundation is a classical geotechnical problem. When a foundation is buried deeply in soil, its failure mode differs markedly from the surface footing and is characterized by a mechanism where soil is free to flow around from under the footing to the top. In this case, the failure mechanism no longer extends to the soil surface, as happens for a shallow foundation, and becomes fully localized around the foundation (O’Neill et al. 2003). The mechanism of soil failure transforms from a general shear failure for a surface footing (Craig 2004) to a localized failure for a buried footing (Hu et al. 1999; Wang and Carter 2002; Hossain and Randolph 2009, 2010; Zhang et al. 2011, 2012, 2014), with the ultimate bearing capacity for a deeply buried foundation demonstrated to be considerably larger than that of a shallow foundation (e.g., Merifield et al. 2001, Zhang et al., 2012). One example, where understanding of the change in bearing capacity at different embedment is required, is the offshore application of spudcan foundations. These large footings of mobile drilling platforms regularly penetrate and bury into the seabed to depths of three diameters (Endley et al. 1981; Menzies and Roper 2008; Menzies and Lopez 2011).

The majority of the previous studies on the bearing capacity problem of buried footings have been limited to homogeneous soil or uniform soil of strength increasing linearly with depth. These have shown that, in uniform soil, a symmetrical logarithmic spiral failure plane for a surface footing and a symmetrical rotational scoop mechanism for a fully buried foundation are optimal (Merifield et al. 2001; Craig 2004). However, under more realistic conditions, soil properties spatially vary due to a combination of geologic, environmental and physical-chemical factors. This spatial variation of soil results in the reduction of the bearing capacity because the failure plane becomes asymmetric and tends to follow the weakest path (e.g., Fenton and Griffiths 2003; Popescu et al. 2005; Cho and Park 2010). The influence of soil spatial variation has been also found in slopes by developing different (shallow or deep) failure planes (Huang et al. 2013).

The bearing capacity of a footing can be overestimated without accounting for the inherent random heterogeneity of soil. Research on the bearing capacity of a surface footing on spatially varying soil has been conducted over the past three decades (e.g. Griffiths and Fenton 2001; Popescu et al. 2005; Kassama and Whittle 2011; Al-Bittar and Soubra 2013). 
Nobahar and Popescu (2000) and Griffiths et al. (2002) observed that the mean bearing capacity can decrease by 20-30\% for random soil compared with the corresponding bearing capacity of homogeneous soil with the same mean soil properties. Cassidy et al. (2013) observed that the mean bearing capacity for pure vertical, horizontal and moment loads decreased with increasing variability of soil strength. The results of such probabilistic studies quantify the bearing capacity reduction. However, few studies have revealed how the spatial variability of random soil affects the failure mechanism and such the bearing capacity. To the authors' knowledge there are no studies on the change in bearing capacity factor for buried footings in spatially random soil.

The objective of this research is to investigate the failure mechanisms and the bearing capacity for footings buried at various depths in random soil. A non-linear finite element analysis combined with a Monte Carlo simulation is employed to achieve the objective. The statistical properties of the bearing capacity are investigated and re-interpreted according to the corresponding failure mechanisms. Finally, the factors of safety at different levels of failure probabilities are proposed. This research provides an improved understanding of the failure mechanisms of buried footings in random soil.

\section{Methodology}

\section{Probabilistic Characteristics of Spatially Random Soil}

All soil properties in situ can vary vertically and horizontally. The spatial variation can be characterized by a trend, which describes the mean value, and a residual variation, which reflects the variability about the trend. The residuals off the trend are statistically correlated to one another in the space and are often a function of their separation distance. The correlation of residuals at two locations separated by distance $\delta$ is called the autocorrelation function. The integral of autocorrelation function results in the scale of fluctuation. The correlation for the properties at two locations within the scale of fluctuation is strong. Details on the physical meaning and characterization of these parameters can be referred to Phoon and Kulhawy (1999) and Baecher and Christian (2003). In this study, the randomness of the undrained shear strength $s_{u}$ is considered and modeled as a log-normally distributed random field with a mean value $\mu_{s}$, standard deviation $\sigma_{s}$, and scale of fluctuation $\theta_{s}$. The Young's modulus $E$ is also a random field, as it is perfectly correlated to the undrained shear 
strength $s_{u}$ with a ratio $E / s_{u}=500$ (Hu and Randolph 1998).

The statistical properties of the undrained shear strength are presented in Table 1. While the mean and standard deviation are familiar concepts to most engineers, the scale of fluctuation requires more examination. Phoon and Kulhawy (1999) conducted an extensive literature review and observed that the horizontal scale of fluctuation $\theta_{h}$ is on the order of 40-60 m (with a mean value from the reported literature of $50.7 \mathrm{~m}$ ). The vertical scale of fluctuation $\theta_{v}$ is in the range of 2-6 m (with a mean value of $3.8 \mathrm{~m}$ ). In this study, a square exponential model (Baecher and Christian 2003) is used to describe the auto-correlation of the undrained shear strength. The scale of fluctuation values is taken as $50.7 \mathrm{~m}$ and $3.8 \mathrm{~m}$ in the horizontal and vertical directions, respectively. The coefficient of variation of the undrained shear strength (i.e., $\sigma_{s} / \mu_{s}$ ) is assumed to be 0.3 in the following simulations as it is reported in the range of 0-0.5 (Uzielli et al. 2005). Random fields of undrained shear strength $s_{u}$ have been generated using the local average subdivision algorithm (Fenton and Vanmarcke 1990).

\section{Random Finite Element Modeling}

The two-dimensional plane strain condition has been simulated using the non-linear finite element software ABAQUS (Dassault Systèmes 2010). A footing (with width of $B$ and height of $h$ ) embedded in a soil of depth $D$ is illustrated in Fig. 1. The soil is modeled with a linear-elastic perfectly-plastic constitutive law. The elastic response is defined by the Young's modulus and the Poisson's ratio. The Poisson's ratio is set as 0.49 to model the undrained conditions of no volume change as well as to ensure numerical stability (Taiebat and Carter 2000). Soil failure is defined according to the Tresca criterion, with the maximum shear stress in any plane limited to the undrained shear strength $\left(s_{u}\right)$.

The foundation width $B$ is $20 \mathrm{~m}$, and the height $h 4 \mathrm{~m}$. These dimensions are typical values for a spudcan foundation today (Cassidy et al. 2009). The embedment depth, $D$, is taken as $0,0.5 \mathrm{~B}, 1 B, 2 B, 3 B$ and $4 B$, respectively. For a foundation deeper than $4 \mathrm{~B}$ its failure is contained in a localized area around the foundation which is not influenced by the embedment depth any more (Rowe and Davis 1982; Randolph et al. 2004; Zhang et al. 2011). The foundation is considered to be rigid and "wished-in-place". The soil-foundation interface is fully 'bonded', which is reasonable to 
represent undrained soil behavior (Gourvenec and Randolph 2003). In the numerical modeling, the foundation is

displaced at the foundation reference point in the vertical direction until a failure load is attained.

The soil domain has a width of $6.4 B$ and a height of $6 B$, which is large enough to ensure there are no obvious boundary effects. The soil domain is discretized into many zones onto which the random field is to be mapped. Hence, the zone size has to be carefully examined to avoid excessive spatial averaging in the finite element modeling. Ching and Phoon (2013) have investigated the effect of zone sizes and observed that the zone size should be 0.13-0.18 times the scale of fluctuation when the squared exponential auto-correlation is adopted. In this case the zone sizes are set to be $2.0 \mathrm{~m}$ in the horizontal direction and $0.5 \mathrm{~m}$ in the vertical direction, which can assure both a prescribed accuracy and an acceptable computational time. The soil properties vary from zone to zone to reflect the spatial variability of the soil. For the majority of the soil domain, a zone is represented by one finite element. However, in a region of size 3B by 2B close to the strip footing (as bounded by the bold lines in Fig. 1), a zone is further discretized into four finite elements of 0.5 x $0.5 \mathrm{~m}$. These smaller elements, each with the same material properties, have been proved to be helpful in improving the numerical accuracy of the simulation (Cassidy et al. 2013).

\section{Monte Carlo Simulation}

For each foundation at a specific embedment depth, Monte Carlo simulations have been performed for $n$ realizations of the soil random field and the subsequent finite element simulations of the bearing capacity. The error in the estimate of the mean shear strength decreases as the number of simulations $n$ increases. The number of simulations $n$ that estimate the mean shear strength to within an error of $e$ with confidence (1- $\alpha)$ is (Fenton and Griffiths 2008)

$$
\mathrm{n} \approx\left(\frac{\mathrm{z}_{\alpha / 2} \sigma_{s}}{\mathrm{e}}\right)^{2}
$$

where $z_{\alpha / 2}$ is the value of the standard normal variant with a cumulative probability level (1- $\left.\alpha / 2\right)$. If a maximum error $e$ of $0.1 \sigma_{s}$ is allowed on the mean value (i.e., maximum error of $3 \%$ on the mean value) of the shear strength with confidence of $95 \%$, the required number of simulations is 385. In this study, 400 simulations have been performed for each foundation at a specific embedment depth. Each realization, with the same statistical properties, can lead to a quite 

mechanisms and bearing capacities of the foundations.

\section{Results and Discussion}

The computed bearing capacity factor for each realization, $N_{c i}$, can be calculated using

$$
\mathrm{N}_{\mathrm{ci}}=\frac{\mathrm{q}_{\mathrm{fi}}}{\mu_{\mathrm{s}}}
$$

where $q_{f i}$ is the bearing capacity computed for the ith realization. The mean value of the undrained shear strength $\mu_{s}$ is maintained at a constant value of $10 \mathrm{kPa}$, which is the undrained shear strength of the uniform soil in the deterministic analysis.

For each analysis, the bearing capacity increases with increasing applied displacement until plateauing at the failure value (which tended to be at a displacement around $6 \%$ of the footing width). The relationship between the bearing capacity factor and the normalized displacement for a surface footing is demonstrated in Fig. 2a. The 400 realization results from the Monte Carlo simulation are compared with both the corresponding deterministic analysis consisting of uniform soil and the closed form solution (e.g., Prandtl's solution). The bearing capacity factor for the deterministic finite element analysis using uniform soil strength is 5.23, which is $1.7 \%$ higher than the Prandtl solution of 5.14. The reason for this small difference is due to the mesh used, which is to balance the computation time ( 15 min for each buried foundation case) and accuracy. The mean value, cumulative distribution and probability distribution for the 400 realizations are showed in Fig. 2b. A majority of the bearing capacity factors obtained from the Monte Carlo simulations are smaller than that of the deterministic case using uniform soil. This trend indicates the spatial variability of a soil is prone to decrease the bearing capacity of a foundation, a result consistent with the research performed by, amongst others, Griffiths and Fenton (2001) and Kasama and Whittle (2011). The following sections will closely inspect the failure mechanisms of a footing in random soil.

\section{Failure Mechanism of Foundations in Random Soil}

The manner in which the failure plane is formed is discussed in this section. Fig. 3 shows a failure plane development of a 
particular realization of the random field, where the blue regions indicate weaker soil and the red regions indicate stronger soil. The shear strain contours (i.e., the regions in gray color) at different normalized displacements are superimposed on the random field. At the initial stage (as shown in Fig. 3a), the largest strain appeares at the two bottom corners of the foundation. Then, the shear plane develops downwards until a weak layer of soil beneath the foundation is encountered (as depicted in Figs. 3b \&c). The shear plane develops further along the weak soil layer and is then restricted by an overlying stronger layer (see path I in Fig. 3d). In addition, a relatively large shear strain in a weak soil layer at a smaller depth emerges (see path II in Fig. 3d). The shear plane extends further along path II through a relatively weak soil region and touches the soil surface. Finally, a complete failure plane forms accompanied by several other shear planes in weaker soil. The failure plane for the uniform soil is also superimposed in Fig. 3f, which is the Prandtl failure mechanism. turn, led to a greater ultimate bearing capacity (6.34). It is interesting that shear planes in random soil can develop several paths in weak soil instead of a single shear path in the deterministic analysis. The failure plane seems tend to find a shear path that costs the least energy to extend from the corner of the foundation to the soil surface. Therefore, not only the weakest soil but also their distribution within spatial pattern of the random soil will determine the failure plane and thus the bearing capacity.

Fig. 4 illustrates the development of the shear strain for a buried foundation of 3B depth in a realization of random of random soil. In uniform soil, the shear plane is symmetrical for surface footing (as observed in Fig. 5a). In random soil, soil. The largest strains first occur in the weakest soil surrounding the foundation. The shear plane is then developed from the regions with the largest strains in a circular manner to form a back-flow mechanism, where soil flows back over the upper surface of the foundation. The failure plane finally passes through a strong soil region to form a localized failure instead of strictly following the weakest soil path. The failure plane for this footing in uniform soil is also superimposed in Fig. 4d, which exhibits a symmetrical pattern.

The shear plane of different realizations can be markedly different from one another due to different spatial patterns Figs. 5b-f selectively show the failure planes for the surface footings with bearing capacity factors of 2.85, 3.94, 4.98, 5.93 
and 6.34, which covers the full range of bearing capacities. Fig. 5b demonstrates that the failure plane is restricted to a

shallow and narrow area, which mobilizes a small area of soil and leads to a small resistance of the soil and thus a small bearing capacity factor of 2.85. As the failure plane becomes deeper, with more soil mobilized, the bearing capacity factor increases, as demonstrated in Figs. 5c-5f. Fig. 5e shows a comparable failure plane to that in Fig. 5d, while the bearing capacity factor is $16 \%$ larger than that of Fig. $5 \mathrm{~d}$. A close examination reveals that the shear strength of the soil along the shear plane in Fig. 5e is generally larger than that in Fig. 5d. Therefore, both the size of the shear plane and the soil strength along the shear plane, with both of them depending on the spatial pattern of the random field, determines the bearing capacity.

The failure planes of the embedded foundation at 3B depth are selected to show different realizations with bearing capacity factors from 8.87 to 12.23 (see Figs. 6b-f). The failure plane for the footing in uniform soil is also shown in Fig. 6a as a comparison. Generally, the bearing capacity increases upon enlarging the shear plane. The shear plane in random soil exhibits an unsymmetrical characteristic which is different from the uniform soil case. Interestingly, the figure suggests that more than one failure plane may be formed, which is different from the common assumption of one failure plane in previous studies (e.g., Fenton and Griffiths 2003). The shear plane in Fig. 6e is larger than that in Fig. 6a, while the bearing capacity factor of the former (i.e., 11.46) is smaller than that of the latter (i.e., 11.86). The reason lies in that the shear plane follows the weakest path in random soil, which has smaller shear strengths along the shear plane than uniform soil.

The failure plane in Fig. $6 \mathrm{f}$ appears to be quite close to the boundary of the soil. Hence, a simulation with a larger boundary (i.e., 12.8B x 6B) has been performed to investigate the boundary effect. The shear plane for this simulation is shown in Fig. 7, which is similar to that in Fig. 6f. The bearing capacity for this analysis is 12.40, which is only $1 \%$ larger than that of Fig. 6f. From this, the boundary size used in the simulations (especially in Fig. 6f) is therefore considered appropriate.

\section{Bearing Capacity Results for Foundations at Different Embedment Depths}


Based on a Monte Carlo simulation for each foundation at a specific embedment depth, the computed bearing capacity factors from Eq. (2) are plotted in the form of histogram, as presented in Fig. 8. A normal distribution is used to fit the histogram (Fig. 8). A Chi-square goodness-of-fit test (Ang and Tang 2007) is performed to verify the assumed normal distribution. Table 2 summarizes the mean value and $\chi^{2}$ statistics for the foundations at six different depths. The $\chi^{2}$ value is in the range of 11-37, which indicates an acceptable probability distribution in most cases (Ang and Tang 2007). This normal distribution of the bearing capacity factor has been also reported for a surface footing by Kasama and Whittle (2011).

depths of $0,0.5 \mathrm{~B}, 1 \mathrm{~B}, 2 \mathrm{~B}, 3 \mathrm{~B}$ and 4B, respectively (see Fig. 9a). The average bearing capacity factors increase with

\section{Probability of Failure for Foundations at Different Embedment Depths}



this paper, we focus on the bearing capacity. According to Griffiths and Fenton (2001) the failure can be defined as the bearing capacities of the foundation being less than the corresponding deterministic values based on the uniform soil strength. The failure can then be defined as the normalized bearing capacity factor of a foundation, $N_{c} / N_{c, \text { det }}$, which is less than 1 . The probability of failure can be easily determined from the cumulative probabilities of the normalized bearing capacity for the foundations (as illustrated in Fig. 10). The failure probabilities are 82.3\%, 87.3\%, 91.7\%, 95.3\%, 95.5\% and $93.3 \%$ for the foundations buried at $0,0.5 \mathrm{~B}, 1 \mathrm{~B}, 2 \mathrm{~B}, 3 \mathrm{~B}$ and $4 \mathrm{~B}$ depths, respectively. The results demonstrate that the deeply embedded foundation generally has a larger probability of failure. is used to define the failure criteria. In reality, the allowable load is often obtained by applying a factor of safety, FS. The probability that the bearing capacity is less than a targeted level of applied load can be determined by considering the factor of safety. The probability of failure can be defined as the bearing capacity being less than the nominated load (i.e., $\left.N_{c, d e t} / F S\right)$. For a normally distributed bearing capacity factor, the probability of failure can then be calculated using 
the safety factor reaches 1.5 . The failure probability is essentially reduced to nearly zero by increasing the factor of safety

to 2.0 for all of the foundations. Table 3 summarizes the factor of safety for foundations at different depths which predicts

failure probabilities of $10^{-2}, 10^{-3}$, and $10^{-4}$. The partial safety factor that accounts for the uncertainty in shear strength for buried anchors specified by DNV (2012) is 1.3 . This factor of safety indicates a failure probability of $0.1 \%$, which is at a reasonable level. Note that the failure of probability is also dependent on the degree of variation and the scale of fluctuation of the random soil, which requires further study.

\section{Summary and Conclusions}

This paper has demonstrated how the spatial pattern of random soil dominates the development of a failure plane and the ultimate bearing capacity for foundations buried at different depths. Different possibilities of shear planes resulting from different spatial patterns of soil are demonstrated, which can explain the significant discrepancy between the bearing capacity of random soil and that of uniform soil. The following conclusions can be drawn:

(1) A shear plane commences at the weakest soil surrounding the foundation and extends along the weak soil path. Several shear planes can be formed in random soil instead of a single shear path defined by the logarithmic spiral or circular shape in uniform soil.

(2) Generally, the bearing capacity increases upon enlarging the shear planes, which are often unsymmetrical in random is essentially reduced to nearly zero by increasing the factor of safety to 2.0 for all of the foundations at the given level of 
the spatial variation parameters calculated).

\section{Acknowledgments}

This research was undertaken with support from the Australia-China Natural Gas Technology Partnership Fund and the Lloyd's Register Foundation. Lloyd's Register Foundation, a UK registered charity and sole shareholder of Lloyd's Register Group Ltd, invests in science, engineering and technology for public benefit, worldwide. This study comprises part of the activities of the Centre for Offshore Foundation Systems (COFS), currently supported as a node of the Australian Research Council Centre of Excellence for Geotechnical Science and Engineering.

\section{References}

Al-Bittar, T., and Soubra, A. H. (2013). "Bearing capacity of strip footings on spatially random soils using sparse 
Dassault systémes. (2010). Abaqus analysis user's manual. USA.

DNV. (2012). Design and installation of fluke anchors. Recommended practice DNV-RP-E301.

Endley, S. N., Rapoport, V., Thompson, P. J., and Baglioni, V. P. (1981). "Prediction of jack-up rig footing penetration.” Proc. $13^{\text {th }}$ Offshore Technology Conf., Houston, OTC 4144, 285-296.

Fenton, G. A., and Griffiths, D. V. (2003). "Bearing capacity prediction of spatially random $c-\phi$ soils." Can. Geotech. J., 40(1), 54-65.

Fenton, G. A., and Griffiths, D. V. (2008). Risk Assessment in Geotechnical Engineering, John Wiley \& Sons, Hoboken, NJ.

Fenton, G. A., and Vanmarcke, E. H. (1990). “Simulation of rand-fields via local average subdivision.” J. Eng. Mech., 116(8), 1733-1749.

Griffiths, D. V., and Fenton, G. A. (2001). "Bearing capacity of spatially random soil: the undrained clay Prandtl problem revisited.” Géotechnique, 51(4), 351-359.

Griffiths, D. V., Fenton, G. A., and Manoharan, N. (2002). “Bearing capacity of rough rigid strip footing on cohesive soil: Probabilistic study.” J. Geotech. Geoenviron. Eng., 128(9), 743-755.

Gourvenec, S., and Randolph, M. (2003). "Effect of strength non-homogeneity on the shape of failure envelopes for combined loading of strip and circular foundations on clay.” Géotechnique, 53(6), 575-586.

Hossain, M. S., and Randolph, M. F. (2009). “New mechanism-based design approach for spudcan foundations on single layer clay.” J. Geotech. Geoenviron. Eng., 135(9), 1264-1274.

Hossain, M. S., and Randolph, M. F. (2010). “Deep-penetrating spudcan foundations on layered clays: centrifuge tests." Géotechnique, 60(3), 157-170.

Hu, Y., and Randolph, M. F. (1998). “A practical numerical approach for large deformation problems in soil.” Int. J. Numer. and Analytical Methods in Geomech., 22, 327-350.

Hu, Y., Randolph, M. F., and Watson, P. G. (1999). "Bearing response of skirted foundation on nonhomogeneous soil.” J. Geotech. Geoenviron. Eng., 125(11), 924-935. 
Huang, J., Lyamin, A.V., Griffiths, D.V., Krabbenhoft, K., and Sloan, S.W. (2013). “Quantitative risk assessment of landslide by limit analysis and random fields.” Comput. Geotech., 53, 60-67.

Kasama, K., and Whittle, A. J. (2011). "Bearing capacity of spatially random cohesive soil using numerical limit analyses.” J. Geotech. Geoenviron. Eng., 137(11), 989-996.

Menzies, D., and Lopez, C. R. (2011). “Four atypical jack-up rig foundation case histories.” $13^{\text {th }}$ International Conference, The Jack up Platform, London.

Menzies, D., and Roper, R. (2008). “Comparison of Jackup rig spudcan penetration methods in clay.” Proc. $40^{\text {th }}$ Offshore Technology Conference, Houston, USA, OTC 19545.

Merifield, R. S., Sloan, S. W., and Yu, H. S. (2001). “Stability of plate anchors in undrained clay.” Géotechnique, 51(2), 141-153.

Nobahar, A., and Popescu, R. (2000). "Spatial variability of soil properties - effects on foundation design.” Proc. 53 ${ }^{\text {rd }}$ Canadian Geotechnical Conference, Montreal, Québec, 2, 1139-1144.

O’Neill, M. P., Bransby, M. F., and Randolph, M. F. (2003). "Drag anchor fluke-soil interaction in clays.” Can. Geotech. J., 40, 78-94.

Phoon, K. K., and Kulhawy, F. H. (1999). “Characterization of geotechnical variability.” Can. Geotech. J., 36, 612-624.

Popescu, R., Deodatis, G., and Nobahar, A. (2005). “Effects of random heterogeneity of soil properties on bearing capacity.” Probabilistic Eng. Mech., 20, 324-341.

Randolph, M. F., Jamiolkowski, M. B., and Zdravkovic, L. (2004). "Load carrying capacity of foundations.” Advances in Geotechnical Engineering: The Skempton Conference, Thoms Telford, London. 207-240.

Rowe, R. K., and Davis E. H. (1982). “The behavior of anchor plates in clay.” Géotechnique, 32(1), 9-23.

Taiebat, H. A., Carter, J. P. (2000). Numerical studies of the bearing capacity of shallow foundations on cohesive soil subjected to combined loading. Geotechnique, 50(4):409-418.

Uzielli, M., Vannucchi, G., and Phoon, K. K. (2005). "Random field characterization of stress-normalised cone penetration testing parameters.” Géotechnique, 55(1), 3-20. 
Wang, C. X., and Carter, J. P. (2002). "Deep penetration of strip and circular footings into layered clays.” Int. J. Geomech., 2(2), 205-232.

Zhang, Y. H., Bienen, B., Cassidy, M. J., and Gourvenec, S. (2011). “The undrained bearing capacity of a spudcan foundation under combined loading in soft clay.” Mar. Struct., 24, 459-477.

Zhang, Y., Bienen, B., Cassidy, M.J., Gourvenec, S. (2012). Undrained bearing capacity of deeply buried flat circular foundations under general loading. Journal of Geotechnical and Geoenvironmental Engineering, ASCE. Vol., 138, No. 3, pp. 385-397.

Zhang, Y., Wang, D., Cassidy, M.J., Bienen, B. (2014). Effect of installation on the bearing capacity of a spudcan under combined loading in soft clay. Journal of Geotechnical and Geoenvironmental Engineering, 